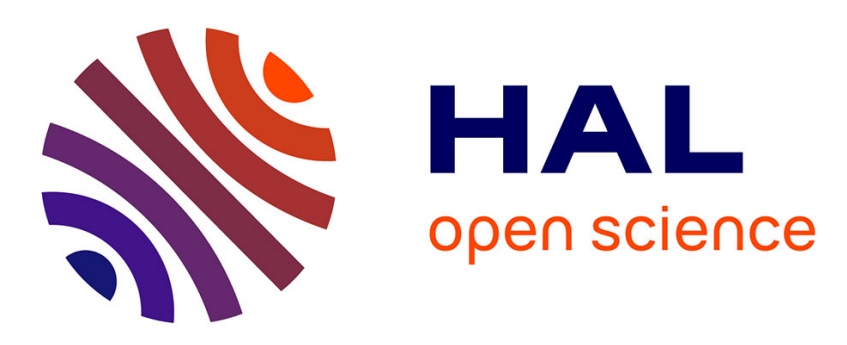

\title{
Development and evaluation of a new procedure for subject-specific tensioning of finite element knee ligaments
}

Bhrigu K. Lahkar, Pierre-Yves Rohan, Helene Pillet, Patricia Thoreux, Wafa Skalli

\section{To cite this version:}

Bhrigu K. Lahkar, Pierre-Yves Rohan, Helene Pillet, Patricia Thoreux, Wafa Skalli. Development and evaluation of a new procedure for subject-specific tensioning of finite element knee ligaments. Computer Methods in Biomechanics and Biomedical Engineering, 2021, 24 (11), pp.1195-1205. 10.1080/10255842.2020.1870220 . hal-03479650

\section{HAL Id: hal-03479650 https://hal.science/hal-03479650}

Submitted on 14 Dec 2021

HAL is a multi-disciplinary open access archive for the deposit and dissemination of scientific research documents, whether they are published or not. The documents may come from teaching and research institutions in France or abroad, or from public or private research centers.
L'archive ouverte pluridisciplinaire HAL, est destinée au dépôt et à la diffusion de documents scientifiques de niveau recherche, publiés ou non, émanant des établissements d'enseignement et de recherche français ou étrangers, des laboratoires publics ou privés. 


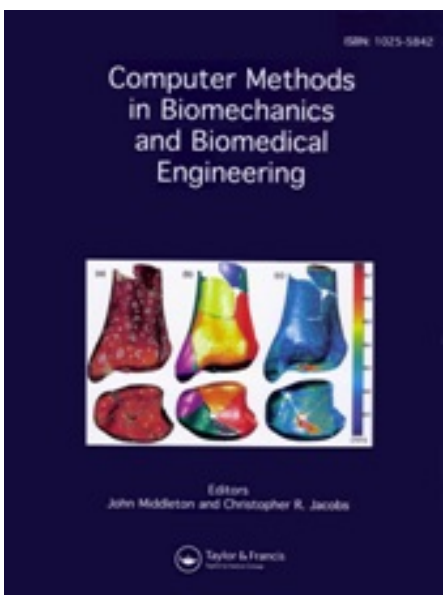

\section{Development and evaluation of a new procedure for subject-specific tensioning of finite element knee ligaments}

\begin{tabular}{|r|l|}
\hline Journal: & Computer Methods in Biomechanics and Biomedical Engineering \\
\hline Manuscript ID & GCMB-2020-0206.R1 \\
\hline Manuscript Type: & Research Article (5500 words) \\
\hline Author: & n/a \\
\hline Complete List of Authors: & $\begin{array}{l}\text { Lahkar, Bhrigu; Arts et Metiers ParisTech, Institut de Biomécanique } \\
\text { Humaine Georges Charpak } \\
\text { Rohan, Pierre-Yves; Arts et Metiers ParisTech, Institut de Biomecanique } \\
\text { Humaine Georges Charpak } \\
\text { Pillet, Hélène; Arts et Metiers ParisTech, Institut de Biomécanique } \\
\text { Humaine Georges Charpak } \\
\text { Thoreux, Patricia; Arts et Metiers ParisTech, Institut de Biomécanique } \\
\text { Humaine Georges Charpak; Université Sorbonne Paris Nord } \\
\text { Skalli, Wafa; Arts et Metiers ParisTech, Institut de Biomécanique } \\
\text { Humaine Georges Charpak }\end{array}$ \\
\hline Keywords: & $\begin{array}{l}\text { Finite Element Analysis, Ligament Prestrain, Subject-Specific Knee } \\
\text { Model, Joint Kinematics, Model Evaluation }\end{array}$ \\
\hline
\end{tabular}

\section{SCHOLARONE \\ Manuscripts}


1

2

3

4

5

6 AUTHORS

7 Bhrigu K. Lahkar ${ }^{1}$ *, Pierre-Yves Rohan ${ }^{1}$, Helene Pillet ${ }^{1}$, Patricia Thoreux ${ }^{1,2}$, Wafa Skalli ${ }^{1}$

\section{AFFILIATIONS}

$9{ }^{1}$ Institut de Biomécanique Humaine Georges Charpak, Arts et Métiers ParisTech, Paris, 10 France

$11{ }^{2}$ Université Sorbonne Paris Nord, Bobigny, France

12

19 Total Word Count (Introduction to Reference): 5452

20 Word count (Abstract): 104

\section{Research Article}

\section{finite element knee ligaments}

*Corresponding author: Bhrigu K. Lahkar

Institut de Biomécanique Humaine Georges Charpak, Arts et Métiers ParisTech, 151

Boulevard de l'Hôpital, 75013 Paris, France

E-mail address: bhrigu_kumar.lahkar@ensam.eu

Tel: +33611745748 


\begin{abstract}
26 Abstract
27 Subject-specific tensioning of ligaments is essential for the stability of the knee joint and 28 represents a challenging aspect in the development of finite element models. We aimed to 29 introduce and evaluate a new procedure for the quantification of ligament prestrains from 30 biplanar X-ray and CT data. Subject-specific model evaluation was performed by comparing 31 predicted femorotibial kinematics with the in vitro response of six cadaveric specimens. The 32 differences obtained using personalized models were comparable to those reported in similar 33 studies in the literature. This study is the first step towards the use of simplified, personalized 34 knee FE models in clinical context such as ligament balancing.
\end{abstract}

35

36

$37 \quad$ Keywords

38 Model Evaluation 


\section{Introduction}

The knee joint is highly susceptible to frequent injury of ligaments. If it remains untreated, has the probability of limiting joint stability, and can further lead to progression of joint arthritis (Fleming et al. 2005). In such scenario, early stage clinical intervention e.g., ligament repair or replacement is often recommended. For such therapeutic interventions and to properly plan surgical procedures, accurate knowledge of the biomechanical behavior of knee ligaments is fundamental.

Several experiments dealing with main knee ligaments (anterior cruciate ligament (ACL), posterior cruciate ligament (PCL), lateral collateral ligament (LCL) and medial collateral ligament (MCL)) have been carried out in the literature (Gardiner et al. 2001; Yoo et al. 2010; Aunan et al. 2012; Belvedere et al. 2012; Rochcongar et al. 2016; Pedersen et al. 2019). Although these studies have substantially increased knowledge on joint functions, yet the complexity of measurements, lesser availability of cadavers, ethical and cost implications have made data acquisition challenging.

Alternatively, finite element (FE) models are commonly used as a reliable complementary means to experimental studies providing significant insight into knee joint biomechanics. A variety of modeling techniques have been utilized to model the joint structure, particularly ligaments. Some of the strategies are steered by simplicity, while others concentrate on faithful capture of specimen-specific anatomy with varying levels of joint representation fidelity. For example, some models included 3D geometries of ligaments with complex material behavior (Limbert et al. 2004; Peña et al. 2005; Kiapour et al. 2014; Orsi et al. 2016). Such approach allows to consider ligament wrapping behavior and analysis of local biomechanical response (e.g., 3D stresses and strains across tissue). Nevertheless, higher anatomically complex models require detailed image-based information of the soft tissue structures under consideration. Generation and simulation of such models often require manifold higher time than that for 
simpler models (Bolcos et al. 2018). Therefore, simpler models may be beneficial for studies where higher number of subjects need to be analyzed and, at the same time, capable of predicting joint mechanics.

In an attempt for model simplification, other authors have proposed to represent ligaments as bundles of springs or tension only cables (Moglo and Shirazi-Adl 2005; Adouni and ShiraziAdl 2009; Baldwin et al. 2012). Although ligaments are exposed to both compressive and tensile states of stress, yet the contribution of tensile stress is substantially higher than others (Peña et al. 2006; Orsi et al. 2016). Therefore, such simplification is considered reasonable and recommended particularly for predicting joint kinematics (Naghibi Beidokhti et al. 2017). Nevertheless, personalization of ligament properties (stiffness and prestrain), although clinically essential to restore joint stability, yet represents a challenge for the community. For example, there is a consensus that graft under-tensioning could lead to joint laxity, which is biomechanically analogous to a ligament deficient knee (Sherman et al. 2012). In addition to that, owing to variable morphology, different bundles of a ligament (e.g., two main fiber bundles of ACL) may exhibit variable prestrain by becoming active at different flexion angles (Girgis et al. 1975). From a modeling perspective, it has also been reported that incorrectly applied ligament prestrain can have a considerable effect on the kinematics of the knee (Mesfar and Shirazi-Adl 2006; Rachmat et al. 2016). To tackle this issue, some authors made subjectspecific adjustment using inverse methods to calibrate specific ligament constitutive behavior. Models either used laxity tests (Baldwin et al. 2012; Naghibi Beidokhti et al. 2017) or distraction loading (Zaylor et al. 2019) to estimate ligament properties by minimizing differences between model-predicted and experimental kinetics. Such calibrations are, however, likely to be computationally expensive.

In light of the above considerations, we proposed an original framework for calibrating subject-specific tensioning of FE knee ligaments based on experimentally acquired data. 
98 Subject-specific model evaluation was performed by comparing predicted femorotibial

kinematics under passive flexion with the experimental data of six cadaveric specimens. We hypothesized that the employed methodology of building personalized FE models with experiment-based prestrains could predict overall passive kinematics of the knee joint.

\section{Materials and methods}

The overall workflow of generating specimen-specific FE mesh is presented in figure 1

\section{[Figure 1 here]}

\subsection{Experimental data acquisition}

We obtained the experimental knee kinematic responses in a previous study (Rochcongar et al. 2016). The experimental procedure is recalled briefly hereafter. Six fresh-frozen lower limb specimens harvested from subjects with age range 47 to 79 years, were tested under passive flexion-extension on a previously validated kinematic test-bench (Hsieh and Draganich 1997; Azmy et al. 2010). Skin and muscles were removed except eight centimeters of quadriceps tendon and popliteus muscle prior to the kinematic data collection. All other relevant joint soft tissue structures (such as ligaments, articular capsule) were kept intact during kinematic data acquisition. The femur was kept fixed, and flexion movement was introduced to the tibia by a rope and pulley system. During flexion, the positions of the three marker tripods placed on the femur, tibia, and patella were recorded using an optoelectronic system (Polaris, Northern Digital Inc., Canada). These recorded positions allowed establishing ancillary reference frames (referred to as $\left.R_{-} A N C_{\mathrm{POL}}(t)\right)$ from $t=0$ (before applying flexion load) till the end of flexion (Figure 1(a)). Measurement uncertainties with the optoelectronic system was previously assessed. Overall uncertainties of less than $0.5 \mathrm{~mm}$ in translational and $1^{\circ}$ in rotational DoF were obtained (Azmy et al. 2010).

In addition, two orthogonal radiographs of each specimen were acquired using an EOS biplanar X-ray system (EOS, EOS-imaging, France) to obtain 3D digital models of the bones 
and tripod markers. From the 3D models, anatomical reference frames (referred to as $R_{-} A N A T_{\mathrm{EOS}}$ ) for the femur, tibia, and patella were defined (Schlatterer et al. 2009). Ancillary reference frames (referred to as $R_{-} A N C_{\mathrm{EOS}}$ ) from the tripod markers were also defined allowing a relationship between anatomical frames and ancillary frames, termed as $M_{-} A N A T_{-} A N C$ (Figure 1(b)). This relation was further used for converting acquired kinematic data, $R \_A N C_{\mathrm{POL}}$ $(t)$ to relative patellofemoral and tibiofemoral motions in the femur anatomical reference frame with Cardan sequence $Z Y^{\prime} X^{\prime \prime}$.

\section{After the kinematic data acquisition, each specimen was fully dissected to identify the}

ligament attachment sites. Absence of trauma and integrity of soft tissue structures was checked during the dissection. An experienced surgeon identified the origin and insertion locations for the following ligaments: anteromedial (AM) and posterolateral (PL) bundles of ACL, posteromedial (PM) and anterolateral (AL) bundles of PCL, superficial (MCLs) and deep (MCLd) bundles of MCL, and LCL. Identified locations were marked with radio-opaque paints, and the bones were scanned using a computed tomography (CT) scanner (Philips, Best, The Netherlands). 3D digital models of each dissected specimen were acquired using MITKGEM (version 5.0) giving anatomical frames $\left(R_{-} A N A T_{\mathrm{CT}}\right)$ and ligament attachment sites ( $P_{-} L I G A_{\mathrm{CT}}$ ) in the $\mathrm{CT}$ scanner system of reference (Figure 1(c)). 3D Digital models and digital footprints of ligament attachment sites were then registered into experimental initial configuration. Registration was performed with biplanar X-ray data. Once the centroidal coordinates of the attachment sites were known, the end-to-end distance of the ligaments origin and insertion site was computed at experimental initial configuration. For the sake of readability, end-to-end distance will be referred to as ligament length hereafter.

\subsection{Initial bone pose estimation}


146 Relative pose (position and orientation) of tibia and patella w.r.t. the femur at initial unloaded

147 configuration was obtained using the relation $M_{-} A N A T_{-} A N C$ and experimental kinematic data, $148 \quad R_{-} A N C_{\mathrm{POL}}(t)$ at time $=0$ (Figure $\left.1(\mathrm{~d})\right)$.

\section{$149 \quad$ 2.3. $\quad$ Specimen specific FE model}

$150 \quad$ 2.3.1. FE mesh

151 First, subject-specific FE hexahedral mesh for each bony segment was created based on the 152 subject-specific CT based digital models (Figure 1(e)) (Lahkar et al. 2018). Then, only the 153 surface mesh (4-noded shell element) was kept to represent bones and cartilage to reduce 154 computational cost (Germain et al. 2016). Then, mesh smoothing was performed at the articular surfaces to improve the mesh quality (Taubin 1995).

156 Mesh quality was assessed using standard ANSYS mesh quality indicators: aspect ratio, 157 parallel deviation, maximum angle, Jacobian ratio, and warping factor. The surface accuracy

\subsubsection{Knee joint FE model}

162 Bones were assumed to be isotropic linear elastic with Young's modulus of $12000 \mathrm{MPa}$ (Choi 163 et al. 1990). As the loading pattern in the study is quasi-static, cartilage was assumed as single164 phase linear isotropic material (Eberhardt et al. 1990). Cartilage regions were modeled as cortico-cartilage material and assigned with Young's modulus of $250 \mathrm{MPa}$ to summarize the material properties of cortical bone and cartilage (Germain et al. 2016). A very thin strip of material between bones and cortico-cartilage region were also modeled with intermediate properties (2000 MPa) to limit mechanical discontinuity (Germain et al. 2016) (Figure 2). 


\section{identified locations (Rochcongar et al. 2016). For other ligaments and tendons (femoro-patellar}

ligament, patellar tendon, quadriceps tendon, posterior capsule), general anatomical sites based

on a priori knowledge of an anatomist were used. Each cruciate ligament was represented by

2 bundles (Blankevoort and Huiskes 1991) along with MCL (deep and superficial) (Smith et

al. 2016). Posterior capsule and femoropatellar ligaments were each represented by 8 bundles

(4 bundles in the medial and lateral side each), while quadriceps and patellar tendon as 4

bundles each (Germain et al. 2016) and LCL as one (Meister et al. 2000). All ligaments and

tendons were represented as point-to-point, tension-only cable elements as their contribution

in tension is much higher than that in compression (Baldwin et al. 2009; Harris et al. 2016).

Three frictionless surface-to-surface contact pairs were considered: tibia-femur cartilage (medial and lateral) and femur-patella cartilage with augmented penalty solution algorithm.

\subsubsection{Ligament material properties}

Three cases of ligament prestrain values $(\% \varepsilon)$ were considered for cruciate and collateral ligaments. No prestrain values for other ligaments were considered and stiffness $(\mathrm{k})$ values for all the ligaments were adopted or estimated from our previous study (Germain et al. 2016). It is to be noted that constant stiffness values were applied across all specimens.

[Figure 3 here]

Case 1: Generic material properties. Prestrain values for ACL (5\%), PCL (-3\%), MCL (0\%) and LCL (0\%) were adopted from previous study (Germain et al. 2016).

Case 2: Automatic pre-computation from experimental data. For each specimen, ligament and bundle specific prestrains were automatically computed from the experimental ligament lengths using equation 1. This is illustrated for the MCL in figure 3.

\section{Case 3: Combination of automatic pre-computation and further manual adjustment.}


precomputed ligament prestrains. The minimum and maximum bounds for each parameter was

defined from the literature (Blankevoort and Huiskes 1996; Baldwin et al. 2009). Each

parameter at a time was modified by changing the previously assigned value by roughly $10 \%$

and RMS error between numerical and experimental kinematics was observed for each DOF.

Based on the error, a new parameter set was assigned. Thus the procedure was repeated till

rotational and translational RMS error became steady state. Stopping criteria was chosen as

change in RMS error between two consecutive iterations is less than or equal to $0.1^{\circ}$ for

rotational and $0.1 \mathrm{~mm}$ for translation.

$$
\text { prestrain }=\left(\frac{\delta}{L}\right) * 100=\left(\frac{L-L_{0}}{L}\right) * 100
$$

206 where, $\mathrm{L}$ is the experimental ligament length at initial configuration (before application of

207 flexion load), and $\mathrm{L}_{0}$ is the zero-strain length at the end of flexion, with an assumption that 208 ligaments experience no force after the prescribed maximum flexion angle.

209 2.3.4. FE model simulation states

210 Three different configurations were defined to represent different simulation states applicable

211 to all the FE models and all cases of ligament properties. As the models are built from the

212 experimental initial configuration, the first state is referred to as (a) no-load or stress free 213 configuration. The second state corresponds to the configuration after attaining equilibrium 214 under prestrain effect, termed as (b) initial equilibrium configuration (or reference 215 configuration). The third state corresponds to the deformed states of the model upon application 216 of incremental rotational displacements on the tibial malleolus until $70^{\circ}$ of flexion angle 217 (Germain et al. 2016). Knee flexion took place at the third state and referred to as (c) current 218 deformed configuration. Remaining DOFs were left unconstrained. Only geometric non219 linearity was considered for the model simulations. 
220

221 The relative position and orientation of the tibia w.r.t. femur was computed based on their anatomical reference frames, as described in (Schlatterer et al. 2009) and interpreted in the 223 femur anatomical reference frame. One-to-one model evaluation was performed by comparing 224 predicted femorotibial kinematics to experimental measurements throughout flexion motion 225 for both the cases 2 and 3. Specimen specific RMS differences between model-predicted and

242 Estimated ligament stiffness and pre-strain values computed according to the procedure 243

\section{experimental measurements were computed based on values at $1^{\circ}$ interval for a range of flexion}

angle $0-60^{\circ}$. Eventually, RMS difference with experimental data was averaged for all the

\section{Results}

\subsection{Mesh quality}

Quality of individual knee joint FE mesh showed no occurrence of error in terms of ANSYS mesh quality indicators.

\subsection{Surface representation accuracy}

\section{[Figure 4 here]}

FE mesh surface accuracy for the femur, tibia, and patella w.r.t. corresponding CT surface across all specimens were found less than or equal to (mean (2RMS) in mm) $0.04(0.12), 0.06$ $(0.18)$ and $0.05(0.14)$ respectively. Error-values are pictorially represented in figure 4 for specimen 1 for the sake of example.

\subsection{Estimation of subject-specific ligament material properties}

\subsubsection{Case 2: Based on automatic pre-computation from experimental data}

[Table 1a and Table 1b here] described in subsection 2.3.3 (case 2) are presented in Table 1a and Table 1b, respectively. 
244 Positive prestrain denotes tight condition and negative prestrain slack condition. Ligament 245 prestrains showed both ligament-specific and specimen-specific variability.

246 3.3.2. Case 3: Combination of automatic pre-computation and further manual adjustment

[Table 1c here]

248 Estimated ligament pre-strain values computed according to the procedure described in 249 subsection 2.3.3 (case 3) are presented in Table 1c. Ligament stiffness values were kept the 250 same as presented in Table 1a.

251 3.4. One-to-one validation of knee joint kinematics

252 On implementation of the generic ligament properties (case 1), only two FE models out of six 253 achieved full convergence. Convergence in this study refers to successful attainment of mechanical equilibrium (within a default tolerance value of ANSYS) at each load step.

Predicted kinematics showed large deviation from the experimental both in magnitude and trend (not reported in this manuscript as only two models achieved convergence). Using the ligament material properties computed automatically (case 2, Table 1b), 5 models out of 6 achieved convergence throughout $60^{\circ}$ of flexion.

[Figure 5 and Figure 6 here] comparison of model predicted femorotibial kinematics against corresponding in vitro results for all specimens are presented in Figure 5 and Figure 6 for automatically computed prestrains are shown from the reference configuration (state-b) until the end of flexion movement. 
Table 2 summarizes the RMS difference between model-predicted and experimental

269

270

271

272

273

274

275

276

277

278

279

280

281

282

283

284

285

286

287

288

289

290

291

292 kinematics for the range of flexion angle $0-60^{\circ}$ for the two cases (case 2 and case 3 ) of ligament material properties. Since 5 models out of 6 were converged while applying automatically computed ligament prestrains, differences are presented for 5 models.

\section{Discussion}

Subject-specific tensioning of ligaments is essential in developing personalized knee FE models. In this study, we built subject-specific knee FE model with CT-based geometry and evaluated a new procedure for subject-specific calibration of ligaments prestrain from biplanar X-ray data. Predicted femorotibial kinematics of each model was compared to the corresponding in vitro response for three different cases of ligament properties (prestrain). First, we investigated whether the FE models with generic prestrain values can capture interindividual variability of the in vitro kinematics. Second, experimentally obtained prestrains were recruited to the FE models and predicted kinematics were observed (case 2). Third, model kinematics were observed with respect to calibrated ligament properties based on the combination of pre-computed prestrains and further adjustment (case 3). For case 2, RMS differences between model-predicted and experimental results for abduction/adduction and external/internal rotation were less than or equal to $2.4^{\circ}$ and $6.3^{\circ}$ respectively. For translation kinematics, the differences observed were less than or equal to $5.0 \mathrm{~mm}, 1.9 \mathrm{~mm}$ and $1.2 \mathrm{~mm}$ respectively for posterior/anterior, superior/inferior, and lateral/medial motions. For case 3, improvement in model kinematics was observed with RMS differences $1.5^{\circ}$ and $5.3^{\circ}$ for abduction/adduction and external/internal rotation. Differences for posterior/anterior, superior/inferior, and lateral/medial motions were $3.4 \mathrm{~mm}, 1.2 \mathrm{~mm}$ and $2 \mathrm{~mm}$ respectively. These results show that the proposed methodology allows us to obtain a good first approximation of the prestrain values with further manual adjustment to improve the kinematic prediction. 
As far as the authors are aware of, there are numerous challenges exist in determining

294 ligament prestrain. Challenges are linked to both measurement issues and modeling issues.

295 Measurement challenges are mainly methodological issues related to identification of ligament

296 attachment sites and determination of ligament elongation pattern during motion (Woo et al.

297 1990; Gardiner et al. 2001; Belvedere et al. 2012). Because of such difficulties, FE models in

298 general, adopt prestrain values from other studies available in the literature (Yang et al. 2010;

299 Galbusera et al. 2014). As these values are adopted from other experimental studies and not

300 corresponding to the specimen under consideration, thereby cannot be considered as subject-

301 specific. Optimization methods have also been extensively used to calibrate specific ligament

302 constitutive behavior. These approaches particularly used laxity tests to calibrate their models

303 (Baldwin et al. 2012; Naghibi Beidokhti et al. 2017). Such approaches are, although shown

304 effective to attain specimen-specific ligament properties, yet computationally expensive.

305 The current study focused on the development and evaluation of a new procedure for

306 subject-specific tensioning of FE knee ligaments. The proposed procedure builds upon data

307 previously collected during an experimental investigation conducted to identify ligament

308 (cruciate and collateral) attachment sites, and to determine the ligament elongation patterns

309 during passive knee flexion (Rochcongar et al. 2016). The FE model replicates the natural

310 ligament (cruciate and collateral) insertions since these are derived from the radio opaque paint

311 locations painted on the specimens prior to the CT-scan (figure 1). The values obtained were

312 consistent with those experimental measurements reported in the literature (Bicer et al. 2010;

313 Belvedere et al. 2012). It is worth mentioning that because of the lack of experimental data for

314 other ligaments, generic insertion sites were employed. Although, it is difficult to directly

315 compare the estimated prestrains with similar studies in literature because of variability in

316 ligament geometry and material property, yet the prestrain values were found within the range

317 confirmed by others (Wismans et al. 1980; Amiri et al. 2006; Zaylor et al. 2019). Also, most 
of the ligaments were found in tensed state at full extension except PCL, which is overall in agreement with the literature (Blankevoort and Huiskes 1991; Moglo and Shirazi-Adl 2005;

Guess et al. 2016). Similarly, predicted kinematic response also showed good correspondence with the experimental results for all specimens. The experimental-numerical differences found in this study were comparable to similar studies reported in the literature (Harris et al. 2016; Naghibi Beidokhti et al. 2017). For instance, Beidokhti et al. reported an average RMS difference of $3.5^{\circ}$ and $2.8^{\circ}$ respectively for abduction/adduction and external/internal rotations.

For anterior/posterior, superior/inferior and lateral/medial motions the differences were $3 \mathrm{~mm}$, $2.3 \mathrm{~mm}$ and $1.6 \mathrm{~mm}$ respectively. It is worthwhile to mention that when generic properties were used, most of the models couldn't reach convergence. As previously reported by other research teams (e.g., (Schwartz et al., 2019)) focusing on the medial collateral ligament) convergence difficulty appeared in this kind of models when material properties were not personalized. The procedure to compute ligament prestrain directly from experimental data (Case 3) provided satisfactory initial guess, based on which model estimated kinematics were already in good agreement with the experimental data. As this approach appears to be computationally inexpensive (15-20 sec to obtain ligament specific prestrain for a single knee model) and methodologically simple, it may serve as a reliable alternative for estimating subject-specific ligament prestrain values. To be noted that no direct evaluation of the ligament tensions was performed in the present study. The decision to implement the current technique as an alternative has to be conducted with caution. For successful implementation of this technique towards clinics, exhaustive model evaluation under various loading conditions is required including ligament tension and contact stress. Nevertheless, validating joint kinematics as a first step could be valuable to show feasibility of the current approach.

This study contains some considerations and limitations worth highlighting. First, while comparing with experimental kinematics, model-predicted results were shown from 
reference configuration (state-b). It is an auto-equilibrated configuration under the prestrain

344 effect, which is not concurrent with initial experimental configuration and difficult to calibrate.

345 This results in absolute offset from the experimental kinematics (Baldwin et al. 2012), although

346 masked in relative kinematics. Second, we acknowledge that one of the sources of

347 discrepancies between experimental-numerical kinematics may come from model

348 simplifications and assumptions. It is also to be noted that predicted kinematics with a

349 combination of initial guess from experimental data and further manual adjustment displayed

350 closer correspondence to in vitro data. Although the difference is minimal, this may be

351 attributed to the representation of overall joint soft tissue structure with simple ligamentous

352 structures without including cartilage layers and menisci. As the proposed methodology is not

353 based on current state-of-the-art approaches (such as MRI based complex models with detailed

354 soft tissue structures), there was difficulty to obtain subject-specific geometry of cartilage and

355 menisci with available imaging modalities (CT and biplanar X-ray) employed in our study.

356 Such simplification, therefore doesn't hold if we are interested in more detailed local insights,

357 e.g., cartilage contact stress. However, for analysis, such as graft tensioning effect on knee

358 response while reconstructing ACL, such simplification was considered relevant (Peña et al.,

359 2005). Third, exclusion of meniscus may overestimate the role of the ligaments in constraining

360 the joint and providing stability (Harris et al. 2016). However, other studies reported no

361 remarkable influence of meniscus on the assessment of the knee joint kinematics, especially

362 for the flexion range $0^{\circ}-90^{\circ}$ (Amiri et al. 2006; Guess et al. 2010). Fourth, ligaments and

363 tendons were represented as bundles of 1D elements, which may not capture actual ligament

364 length variation, as they do not account for material continuum, fiber twisting or wrapping.

365 Yet, such simplification provides faster solutions and recommended, particularly for the

366 prediction of knee kinematic parameters (Bolkus et al., 2018; Naghibi Beidokhti et al., 2017).

367 Fifth, we chose to personalize only ligament prestrains, although stiffness values vary from 
subject to subject. This consideration was based on sensitivity analyses found in literature, where model predicted kinematics are proclaimed to be highly sensitive to strain state at initial configuration rather than stiffness values (Wismans et al. 1980; Peña et al. 2005). Besides, the models were validated only under passive flexion load, which may not imitate an in-vivo situation of clinical interest, yet could be a first step of assessing the potential of the models towards complex scenarios. In this contribution, a maximum flexion angle of $70^{\circ}$ was considered to calibrate the model as this range covers the most common amplitude of in-vivo motion under level walking, during which ligaments offer a substantial contribution to knee stability (Butler et al. 2007). However, perspective work will focus on calibrating the model up to $120^{\circ}$ of knee flexion. We acknowledge that no influence of experimental uncertainty nor sensitivity of ligament attachment sites on predicted kinematics was performed. Future study is necessary to asses this issue. Finally, the study was limited to six specimens due to time and labor associated with CT segmentation, yet higher in number compared to other similar published studies. This might limit the model at the current state for clinical translation; however, it was imperative to build CT based models to minimize the impact of geometrical uncertainty in model predictions.

In conclusion, as it was a first study to directly implement prestrain values on models directly from the experiment, which may find scopes in model-based clinical studies, such as planning of ligament balancing or reconstruction as it reduces complexity in model development (especially ligament calibration) as well as computational cost, while maintaining good correspondence with experimental data. In that aim, further model evaluation would be necessary for larger specimen size and in other clinically relevant scenarios.

\section{Conflict of Interest}

None 


\section{Acknowledgments}

394 The authors are deeply grateful to the ParisTech BiomecAM chair program on subject-specific 395 musculoskeletal modeling for financial support.

\section{References}

397 Adouni M, Shirazi-Adl A. 2009. Knee joint biomechanics in closed-kinetic-chain exercises. Comput 398 Methods Biomech Biomed Engin. 12(6):661-670.

399 Amiri S, Cooke D, Kim IY, Wyss U. 2006. Mechanics of the passive knee joint. Part 1: The role of the 400 tibial articular surfaces in guiding the passive motion. Proc Inst Mech Eng Part H J Eng Med. $401220(8): 813-822$.

402 Aunan E, Kibsgård T, Clarke-Jenssen J, Röhrl SM. 2012. A new method to measure ligament balancing 403 in total knee arthroplasty: Laxity measurements in 100 knees. Arch Orthop Trauma Surg. 404 132(8):1173-1181.

405 Azmy C, Guérard S, Bonnet X, Gabrielli F, Skalli W. 2010. EOS ${ }^{\circledR}$ orthopaedic imaging system to study 406 patellofemoral kinematics: Assessment of uncertainty. Orthop Traumatol Surg Res. 96(1):28-36.

407 Baldwin MA, Clary C, Maletsky LP, Rullkoetter PJ. 2009. Verification of predicted specimen-specific 408 natural and implanted patellofemoral kinematics during simulated deep knee bend. J Biomech 409 [Internet]. 42(14):2341-2348. http://dx.doi.org/10.1016/j.jbiomech.2009.06.028

410 Baldwin MA, Clary CW, Fitzpatrick CK, Deacy JS, Maletsky LP, Rullkoetter PJ. 2012. Dynamic finite 411 element knee simulation for evaluation of knee replacement mechanics. J Biomech [Internet]. 412 45(3):474-483. http://dx.doi.org/10.1016/j.jbiomech.2011.11.052

413 Belvedere C, Ensini A, Feliciangeli A, Cenni F, D’Angeli V, Giannini S, Leardini A. 2012. Geometrical 414 changes of knee ligaments and patellar tendon during passive flexion. J Biomech [Internet]. 415 45(11):1886-1892. http://www.ncbi.nlm.nih.gov/pubmed/22677336

416 Bicer EK, Lustig S, Servien E, Selmi TAS, Neyret P. 2010. Current knowledge in the anatomy of the 417 human anterior cruciate ligament. Knee Surgery, Sport Traumatol Arthrosc [Internet]. 18(8):1075418 1084. https://doi.org/10.1007/s00167-009-0993-8

419 Blankevoort L, Huiskes R. 1991. Ligament-bone interaction in a three-dimensional model of the knee. 420 J Biomech Eng [Internet]. 113(3):263-269. http://www.ncbi.nlm.nih.gov/pubmed/1921352

421 Blankevoort L, Huiskes R. 1996. Validation of a three-dimensional model of the knee. J Biomech 422 [Internet]. [accessed 2019 Sep 3] 29(7):955-961.

423 https://linkinghub.elsevier.com/retrieve/pii/0021929095001492

424 Bolcos PO, Mononen ME, Mohammadi A, Ebrahimi M, Tanaka MS, Samaan MA, Souza RB, Li X, 425 Suomalainen JS, Jurvelin JS, et al. 2018. Comparison between kinetic and kinetic-kinematic driven 426 knee joint finite element models. Sci Rep [Internet]. [accessed 2019 Aug 29] 8(1):17351.

427 www.nature.com/scientificreports

428 Butler RJ, Marchesi S, Royer T, Davis IS. 2007. The Effect of a Subject-Specific Amount of Lateral 
Wedge on Knee. J Orthop Res Sept. 25(June):1121-1127.

Choi K, Kuhn JL, Ciarelli MJ, Goldstein SA. 1990. The elastic moduli of human subchondral, trabecular, and cortical bone tissue and the size-dependency of cortical bone modulus. J Biomech. 23(11):1103-1113.

Eberhardt AW, Keer LM, Lewis JL, Vithoontien V. 1990. An analytical model of joint contact. J Biomech Eng [Internet]. 112(4):407-413. https://doi.org/10.1115/1.2891204

Fleming BC, Hulstyn MJ, Oksendahl HL, Fadale PD. 2005. Ligament injury, reconstruction and osteoarthritis. Curr Opin Orthop. 16(5):354-362.

Galbusera F, Freutel M, Dürselen L, D’Aiuto M, Croce D, Villa T, Sansone V, Innocenti B. 2014. Material models and properties in the finite element analysis of knee ligaments: A literature review. Front Bioeng Biotechnol [Internet]. 2(NOV):1-11. http://journal.frontiersin.org/article/10.3389/fbioe.2014.00054/abstract

Gardiner JC, Weiss JA, Rosenberg TD. 2001. Strain in the human medial collateral ligament during valgus loading of the knee. Clin Orthop Relat Res.(391):266-274.

Germain F, Rohan PY, Rochcongar G, Rouch P, Thoreux P, Pillet H, Skalli W. 2016. Role of ligaments in the knee joint kinematic behavior: Development and validation of a finite element model. In: Joldes GR, Doyle B, Wittek A, Nielsen PMF, Miller K, editors. Comput Biomech Med Imaging, Model Comput. Cham: Springer International Publishing; p. 15-26.

Guess TM, Razu S, Jahandar H. 2016. Evaluation of Knee Ligament Mechanics Using Computational Models. J Knee Surg. 29(2):126-137.

Guess TM, Thiagarajan G, Kia M, Mishra M. 2010. A subject specific multibody model of the knee with menisci. Med Eng Phys [Internet]. [accessed 2019 Jul 24] 32(5):505-515.

https://linkinghub.elsevier.com/retrieve/pii/S1350453310000494

Harris MD, Cyr AJ, Ali AA, Fitzpatrick CK, Rullkoetter PJ, Maletsky LP, Shelburne KB. 2016. A Combined Experimental and Computational Approach to Subject-Specific Analysis of Knee Joint Laxity. J Biomech Eng. 138(8):081004.

Hsieh YF, Draganich LF. 1997. Knee kinematics and ligament lengths during physiologic levels of isometric quadriceps loads. Knee. 4(3):145-154.

Kiapour A, Kiapour AM, Kaul V, Quatman CE, Wordeman SC, Hewett TE. 2014. Finite element model of the knee for investigation of injury mechanisms: Development and validation. J Biomech Eng. 136(1):011002.

Lahkar BK, Rohan P-Y, Pillet H, Thoreux P, Skalli W. 2018. Fast subject specific finite element mesh generation of knee joint from biplanar $x$-ray images. In: Cmbbe [Internet]. [place unknown]; [accessed 2019 Aug 7]. http://cmbbe2018.tecnico.ulisboa.pt/pen_cmbbe2018/pdf/WEB_PAPERS/CMBBE2018_paper_143.p df

Limbert G, Taylor M, Middleton J. 2004. Three-dimensional finite element modelling of the human ACL: Simulation of passive knee flexion with a stressed and stress-free ACL. J Biomech. 37(11):17231731. 
468 Meister BR, Michael SP, Moyer RA, Kelly JD, Schneck CD. 2000. Anatomy and kinematics of the 469 lateral collateral ligament of the knee. Am J Sports Med. 28(6):869-878.

470 Mesfar W, Shirazi-Adl A. 2006. Biomechanics of changes in ACL and PCL material properties or 471 prestrains in flexion under muscle force-implications in ligament reconstruction. Comput Methods 472 Biomech Biomed Engin [Internet]. 9(4):201-209. https://doi.org/10.1080/10255840600795959

473 Moglo KE, Shirazi-Adl A. 2005. Cruciate coupling and screw-home mechanism in passive knee joint 474 during extension-flexion. J Biomech [Internet]. [accessed 2019 Jul 10] 38(5):1075-1083.

475 https://linkinghub.elsevier.com/retrieve/pii/S0021929004002805

476 Naghibi Beidokhti H, Janssen D, van de Groes S, Hazrati J, Van den Boogaard T, Verdonschot N. 2017. 477 The influence of ligament modelling strategies on the predictive capability of finite element models 478 of the human knee joint. J Biomech [Internet]. [accessed 2019 Jul 12] 65:1-11.

479 https://linkinghub.elsevier.com/retrieve/pii/S0021929017304529

480 Orsi AD, Chakravarthy S, Canavan PK, Peña E, Goebel R, Vaziri A, Nayeb-Hashemi H. 2016. The effects 481 of knee joint kinematics on anterior cruciate ligament injury and articular cartilage damage. Comput 482 Methods Biomech Biomed Engin. 19(5):493-506.

483 Pedersen D, Vanheule V, Wirix-Speetjens R, Taylan O, Delport HP, Scheys L, Andersen MS. 2019. A 484 novel non-invasive method for measuring knee joint laxity in four dof: In vitro proof-of-concept and 485

\section{Peña E, Calvo B, Martínez MA, Doblaré M. 2006. A three-dimensional finite element analysis of the combined behavior of ligaments and menisci in the healthy human knee joint. J Biomech [Internet]. [accessed 2019 Jul 24] 39(9):1686-1701. https://linkinghub.elsevier.com/retrieve/pii/S0021929005002113}

Peña E, Martínez MA, Calvo B, Palanca D, Doblaré M. 2005. A finite element simulation of the effect of graft stiffness and graft tensioning in ACL reconstruction. Clin Biomech. 20(6):636-644.

Rachmat HH, Janssen D, Verkerke GJ, Diercks RL, Verdonschot N. 2016. In-situ mechanical behavior and slackness of the anterior cruciate ligament at multiple knee flexion angles. Med Eng Phys [Internet]. [accessed 2019 Jul 19] 38(3):209-215. https://linkinghub.elsevier.com/retrieve/pii/S1350453315002696

Rochcongar G, Pillet H, Bergamini E, Moreau S, Thoreux P, Skalli W, Rouch P. 2016. A new method for the evaluation of the end-to-end distance of the knee ligaments and popliteal complex during passive knee flexion. Knee [Internet]. 23(3):420-425. http://dx.doi.org/10.1016/j.knee.2016.02.003

Schlatterer B, Suedhoff I, Bonnet X, Catonne Y, Maestro M, Skalli W. 2009. Skeletal landmarks for TKR implantations: Evaluation of their accuracy using EOS imaging acquisition system. Orthop Traumatol Surg Res. 95(1):2-11.

Sherman SL, Chalmers PN, Yanke AB, Bush-Joseph CA, Verma NN, Cole BJ, Bach BR. 2012. Graft tensioning during knee ligament reconstruction: Principles and practice. J Am Acad Orthop Surg. 20(10):633-645.

Smith CR, Vignos MF, Lenhart RL, Kaiser J, Thelen DG. 2016. The influence of component alignment and ligament properties on tibiofemoral contact forces in total knee replacement. J Biomech Eng [Internet]. [accessed 2019 Jun 20] 138(2):021017. https://biomechanical.asmedigitalcollection.asme.org 
Taubin G. 1995. Curve and surface smoothing without shrinkage. IEEE Int Conf Comput Vis.:852-857.

510 Wismans J, Veldpaus F, Janssen J, Huson A, Struben P. 1980. A three-dimensional mathematical

511 model of the knee-joint. J Biomech [Internet]. [accessed 2019 Sep 9] 13(8):677-685.

512 https://linkinghub.elsevier.com/retrieve/pii/0021929080903541

513 Woo SLY, Weiss JA, Gomez MA, Hawkins DA. 1990. Measurement of changes in ligament tension 514 with knee motion and skeletal maturation. J Biomech Eng. 112(1):46-51.

515 Yang NH, Canavan PK, Nayeb-Hashemi H, Najafi B, Vaziri A. 2010. Protocol for constructing subject516 specific biomechanical models of knee joint. Comput Methods Biomech Biomed Engin. 13(5):589517603.

Yoo YS, Jeong WS, Shetty NS, Ingham SJM, Smolinski P, Fu F. 2010. Changes in ACL length at different knee flexion angles: An in vivo biomechanical study. Knee Surgery, Sport Traumatol Arthrosc. 18(3):292-297.

Zaylor W, Stulberg BN, Halloran JP. 2019. Use of distraction loading to estimate subject-specific knee

https://doi.org/10.1016/j.jbiomech.2019.04.040

\section{Figure Captions}

Figure 1. Schematic illustration for (a) kinematic test: position of tripod markers in Polaris coordinate system (CSYS), (b) biplanar X-ray: 3D digital models of bone and tripod markers giving anatomical and ancillary reference frames in EOS CSYS, (c) CT scan: Accurate 3D digital models of bone and ligament attachment sites giving anatomical reference frames and ligament attachment locations in CT CSYS, (d) knee in experimental initial configuration giving anatomical reference frames in Polaris CSYS, (e) CT based subject-specific FE mesh and ligament attachment sites in experimental initial configuration

Figure 2. FE model with soft tissues (only shown for the distal femur and proximal tibia region)

Figure 3. Experimental ligament length change for superficial MCL throughout the flexion movement. A similar strategy was implemented for other ligaments except for PCL, which is based on literature values

Figure 4. Surface representation accuracy as a Hausdorff distance for femur, tibia, and patella

Figure 5. One-to-one comparison of FE model kinematic predictions against corresponding 541 experimental data for (a) - (b): rotational and for (c) - (e): translational femorotibial kinematics 542 interpreted in femur anatomical reference frame. Results reported are based on the implementation of 543 automatically computed ligament prestrains

544 Figure 6. One-to-one comparison of FE model kinematic predictions against corresponding 545 experimental data for (a) - (b): rotational and for (c) - (e): translational femorotibial kinematics 546 interpreted in femur anatomical reference frame. Results reported obtained using a combination of 547 automatic pre-computation and further manual adjustment 
549 Table Headings

550

551 Table 1a Estimated ligament stiffness values for a single specimen

552 Table 1b Automatically computed ligament prestrain values from experimental data (case 2)

553 Table 1c Prestrain obtained with a combination of automatic pre-computation and further manual 554 adjustment (case 3)

555 Table 2 Average RMS difference \pm SD between experimental and model-predicted kinematics 


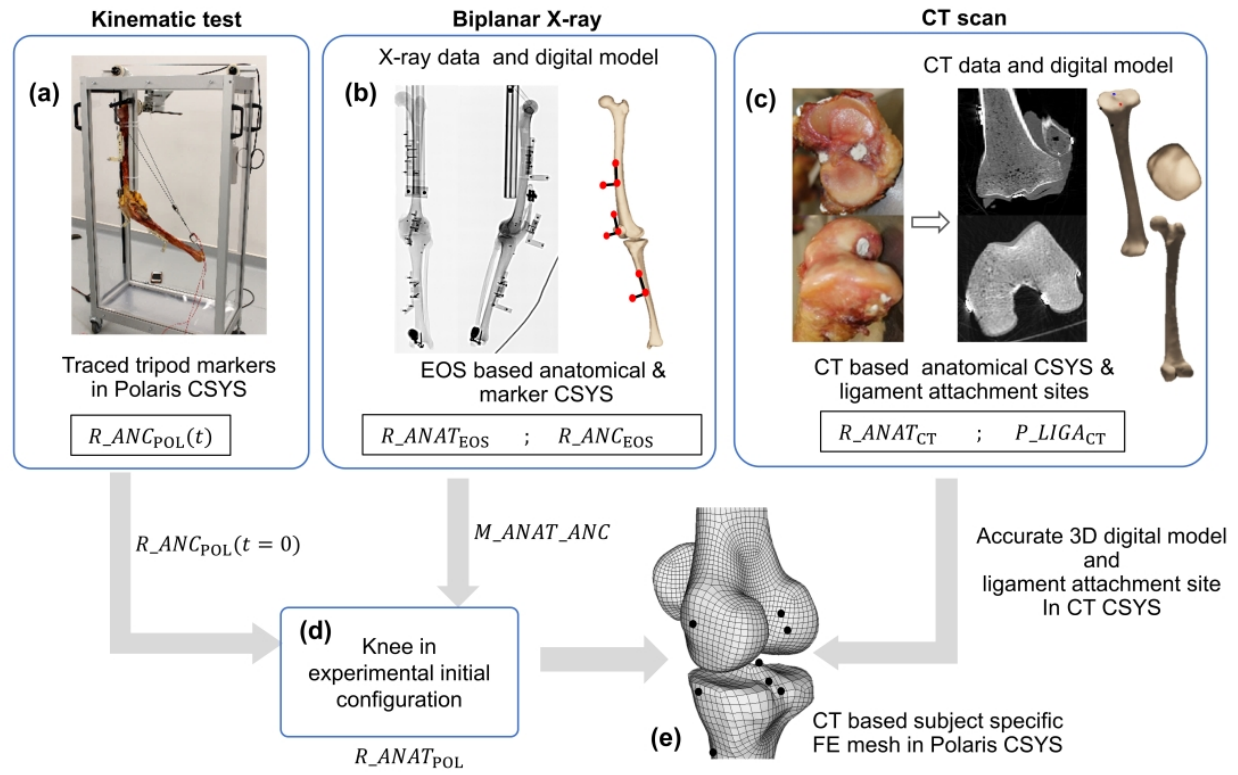

Figure 1

$249 \times 159 \mathrm{~mm}(800 \times 800 \mathrm{DPI})$ 


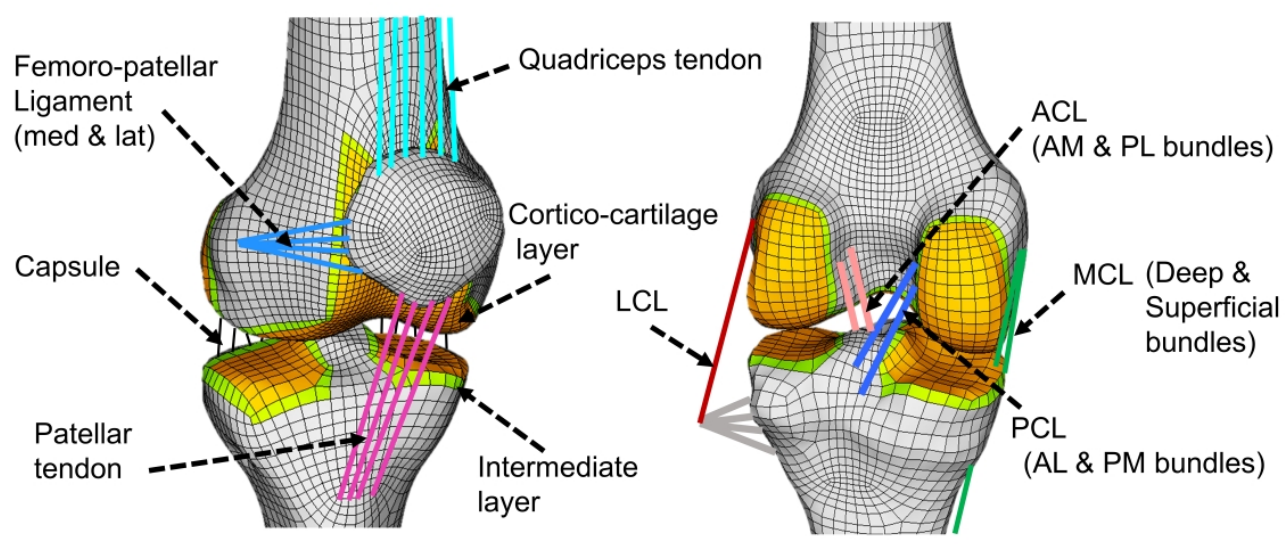

Figure 2

$190 \times 85 \mathrm{~mm}(1200 \times 1200 \mathrm{DPI})$ 


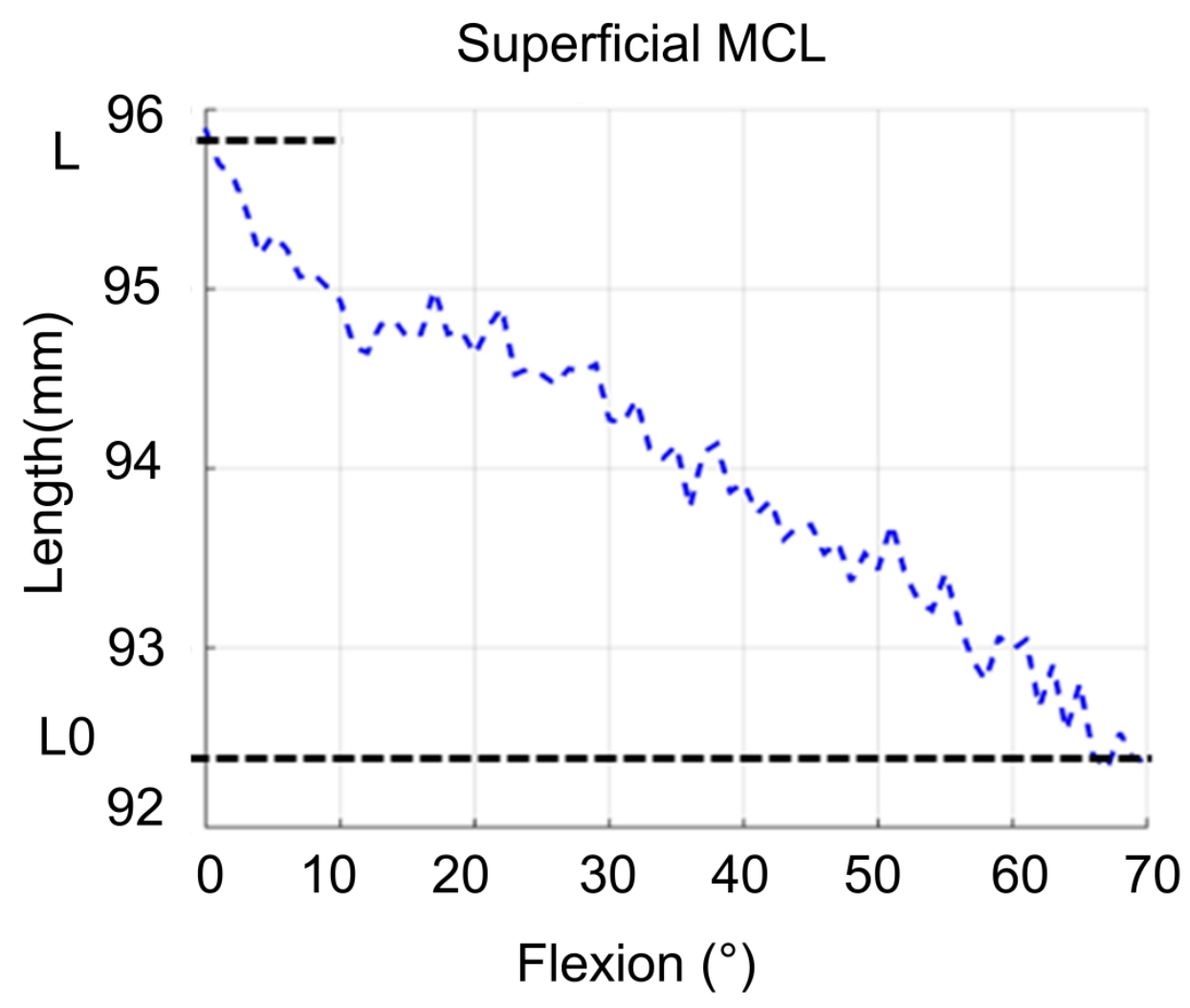

Figure 3

$100 \times 90 \mathrm{~mm}(1200 \times 1200 \mathrm{DPI})$ 


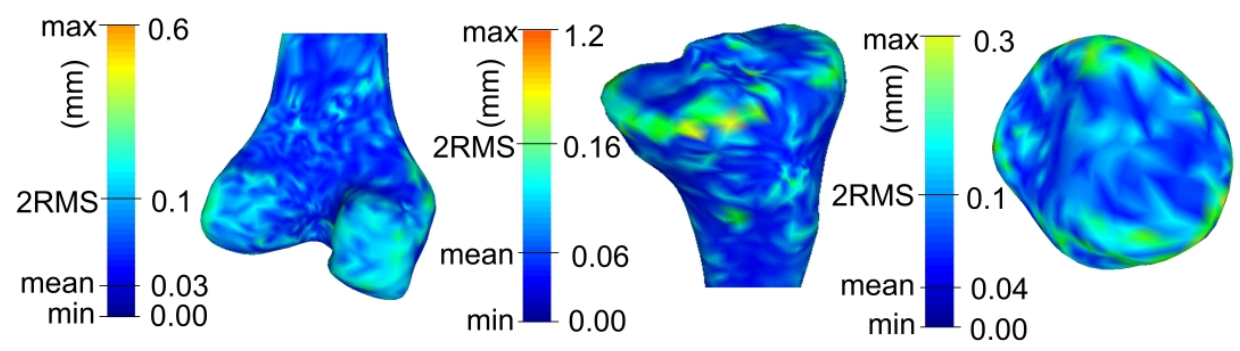

Figure 4

$215 \times 65 \mathrm{~mm}(1200 \times 1200 \mathrm{DPI})$ 

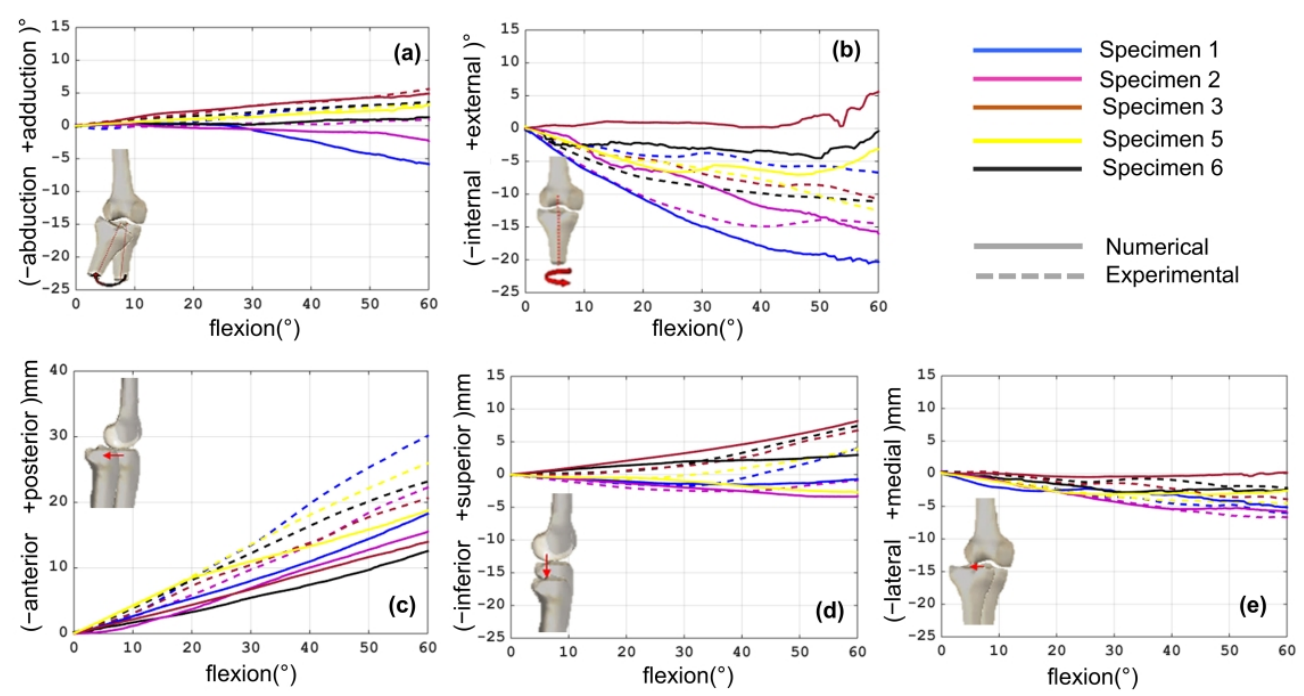

Figure 5

$239 \times 134 \mathrm{~mm}(600 \times 600 \mathrm{DPI})$ 

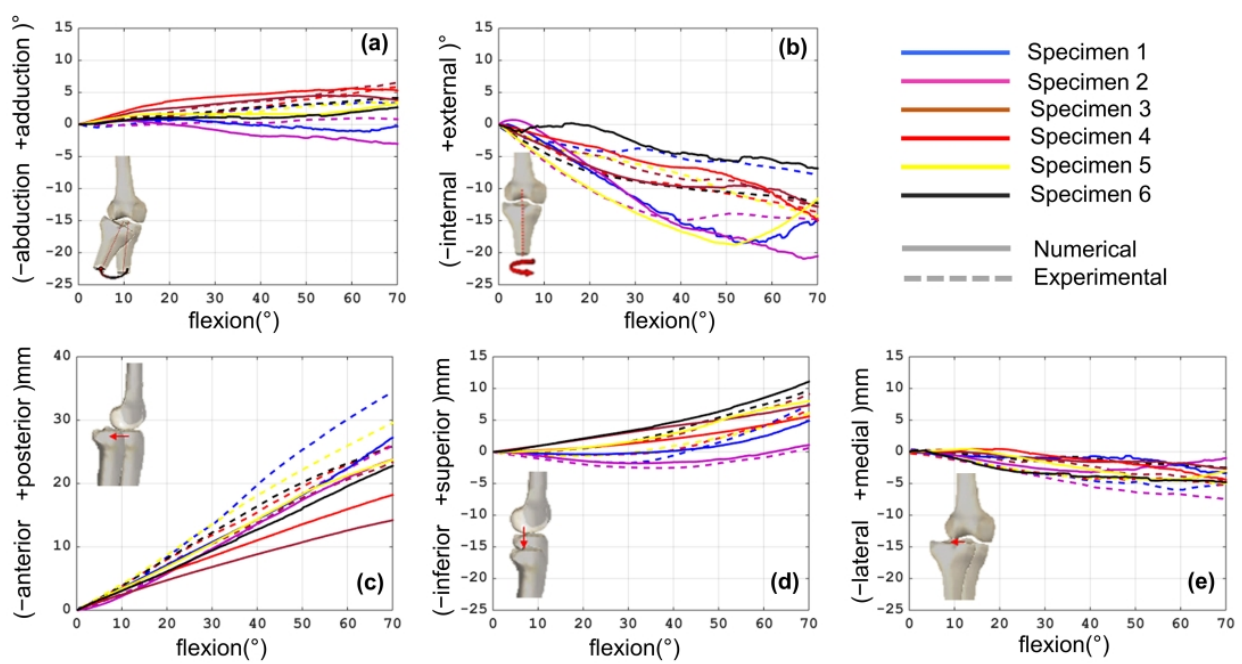

Figure 6

$239 \times 134 \mathrm{~mm}(600 \times 600 \mathrm{DPI})$ 
Table 1a

\begin{tabular}{cccccccc}
\hline Ligaments & \multicolumn{2}{c}{ ACL } & \multicolumn{2}{c}{ PCL } & \multicolumn{2}{c}{ MCL } & LCL \\
\hline Bundles & AM & PL & AL & PM & MCLd & MCLs & \\
\hline Stiffness(N/mm) & 125 & 105 & 125 & 65 & 45 & 25 & 60 \\
\hline
\end{tabular}

Table 1b: Case 2

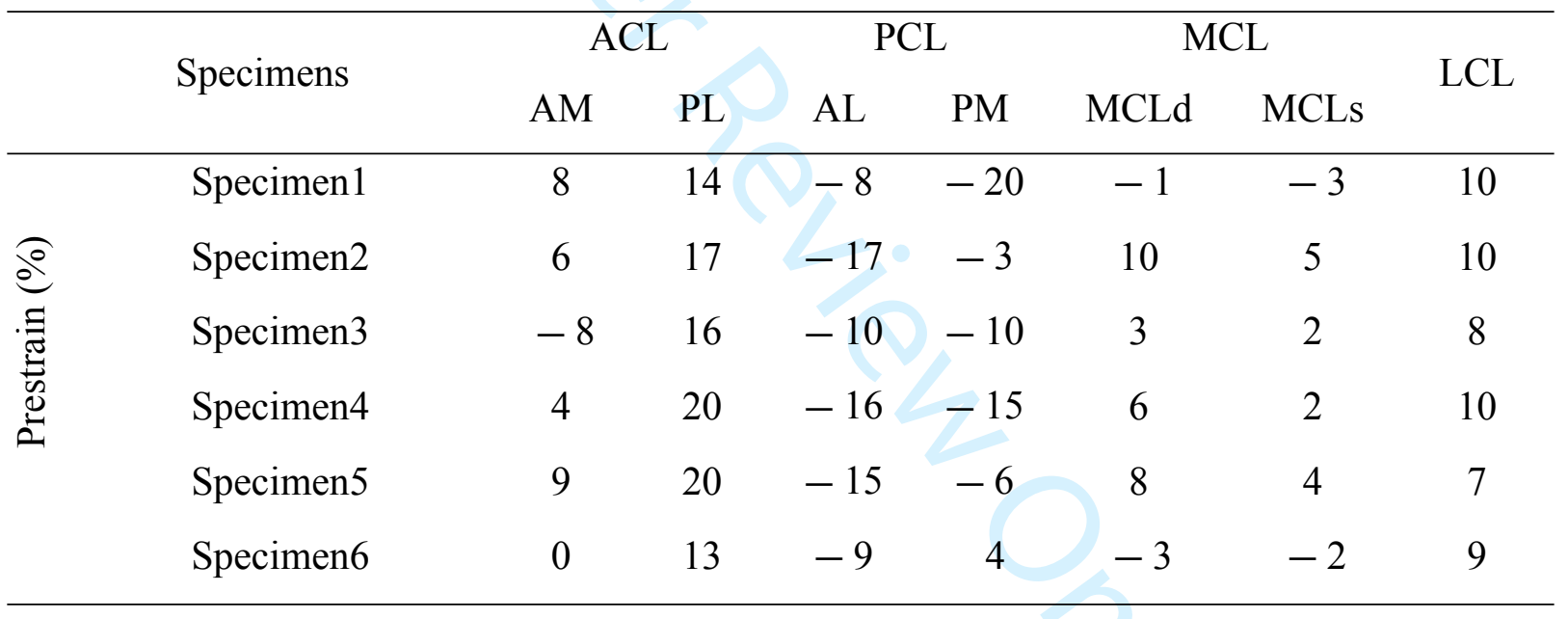


Table 1c: Case 3

\begin{tabular}{|c|c|c|c|c|c|c|c|c|}
\hline & Ligaments & & & & & & & $I C$ \\
\hline & \& Bundles & $\mathrm{AM}$ & PL & $\mathrm{AL}$ & PM & MCLd & MCLs & \\
\hline & Specimen1 & 8 & 10 & -2 & -8 & 8 & 3 & 6 \\
\hline & Specimen 2 & 6 & 12 & -8 & -4 & 6 & 3 & 5 \\
\hline$\underbrace{e}_{=}$ & Specimen 3 & 8 & 10 & -8 & -8 & 2 & 1 & 4 \\
\hline$\underset{\Xi}{\tilde{E}}$ & Specimen4 & 10 & 10 & -9 & -5 & 2 & 3 & 6 \\
\hline 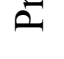 & Specimen5 & 10 & 13 & -5 & -5 & 3 & 2 & 2 \\
\hline & Specimen6 & 6 & 6 & -3 & -3 & 4 & 3 & 3 \\
\hline
\end{tabular}

Table 2

\begin{tabular}{ccccccc}
\hline Flexion & Case & Abd/Add in & Ext/Int in & Post/Ant in $\mathrm{mm}$ & Sup/Inf in $\mathrm{mm}$ & Lat/Med in $\mathrm{mm}$ \\
\hline \multirow{2}{*}{$0-60^{\circ}$} & 1 & - & - & - & - & - \\
\cline { 2 - 7 } & 2 & $2.4 \pm 1.3$ & $6.3 \pm 6.2$ & $5.0 \pm 3.5$ & $1.9 \pm 1.8$ & $1.2 \pm 1.1$ \\
\cline { 2 - 7 } & 3 & $1.5 \pm 1.3$ & $5.3 \pm 5.1$ & $3.4 \pm 2.3$ & $1.2 \pm 0.8$ & $2.0 \pm 1.9$ \\
\hline
\end{tabular}

